Article

\title{
Comparing Food Provided and Wasted before and after Implementing Measures against Food Waste in Three Healthcare Food Service Facilities
}

\author{
Christina Strotmann ${ }^{1, *}$ (D), Silke Friedrich ${ }^{1}$, Judith Kreyenschmidt ${ }^{2}$, Petra Teitscheid ${ }^{1}$ and \\ Guido Ritter ${ }^{1}$ \\ 1 Institute of Sustainable Nutrition (iSuN), Münster University of Applied Sciences, Corrensstr. 25, \\ Münster 48149, Germany; Silke.Friedrich@fh-muenster.de (S.F.); teitscheid@fh-muenster.de (P.T.); \\ gritter@fh-muenster.de (G.R.) \\ 2 Institute of Nutritional and Food Sciences, Cold Chain Management Working Group, University of Bonn, \\ Katzenburgweg 7-9, Bonn 53115, Germany; j.kreyenschmidt@uni-bonn.de \\ * Correspondence: Christina.Strotmann@fh-muenster.de; Tel.: +49-251-8365-572
}

Received: 12 June 2017; Accepted: 8 August 2017; Published: 10 August 2017

\begin{abstract}
The aim of the study was to reduce food waste in a hospital, a hospital cafeteria, and a residential home by applying a participatory approach in which the employees were integrated into the process of developing and implementing measures. Initially, a process analysis was undertaken to identify the processes and structures existing in each institution. This included a 2-week measurement of the quantities of food produced and wasted. After implementing the measures, a second measurement was conducted and the results of the two measurements were compared. The average waste rate in the residential home was significantly reduced from $21.4 \%$ to $13.4 \%$ and from $19.8 \%$ to $12.8 \%$ in the cafeteria. In the hospital, the average waste rate remained constant $(25.6 \%$ and $26.3 \%$ during the reference and control measurements). However, quantities of average daily food provided and wasted per person in the hospital declined. Minimizing overproduction, i.e., aligning the quantity of meals produced to that required, is essential to reducing serving losses. Compliance of meal quality and quantity with customer expectations, needs, and preferences, i.e., the individualization of food supply, reduces plate waste. Moreover, establishing an efficient communication structure involving all actors along the food supply chain contributes to decreasing food waste.
\end{abstract}

Keywords: food waste; food service facilities; resource efficiency; hospital catering; plate waste; serving losses; sustainable nutrition

\section{Introduction}

Kranert et al. [1] found that 65,000 tons of food are wasted in hospitals and 93,000 to 145,000 tons in nursing and residential homes each year in Germany. In addition to the discarded food, all resources used during agricultural and industrial production and transport are also wasted. This contradicts the concept of sustainable nutrition [2] which, in times of scarce resources, is becoming increasingly important with regard to the finiteness of resources, such as land, energy, water, and other assets. For this reason, politicians and customers expect the food industry and caterers to accept responsibility for their diners, society, and the environment [3].

In their review article, Williams and Walton [4] summarized the literature on the extent of plate waste occurring in hospitals until 2011. They found a median plate waste of $30 \%$, with a wide range from 6 to $65 \%$, reported in 32 international studies. The findings of current research coincide with earlier results. Sonnino and McWilliam [5] determined that the total food waste in three Welsh hospitals ranged from $19 \%$ to $66 \%$. In the Irish 3-year Green Healthcare Programme of the Environmental 
Protection Agency, 37\% and 49\% of the food prepared for and provided to patients was wasted [6]. Similar findings were revealed in a Portuguese study, in which Dias-Ferreira et al. [7] found that an average of $35 \%$ of food served was not consumed by patients but discarded as waste. In the study by Ofei et al. [8] conducted in a Danish hospital, unserved food items totaled 50\% of every lunch and supper for wards with a satellite kitchen as well as $42 \%$ and $65 \%$ for wards without a satellite kitchen. The above findings reveal a great reduction potential for food waste in the healthcare sector.

Other studies from the food service sector that address the economic perspective of food waste emphasized that reducing food waste also offers financial benefits. Engström and Carlsson-Kanyama [9] found in four Swedish service institutions that there is a $20 \%$ loss on average, with plate waste accounting for about $50 \%$ of waste as the single largest source. They extrapolated that 287 million additional portions could be served from food discarded in the food service industry in Sweden, and calculated economic losses of $€ 657$ (SEK 6030, July 2003) per day for the four restaurants under investigation. Barton et al. [10] estimated that the food wasted on four hospital wards was worth $£ 139,655$ (€160,889, June 2017) during the four-week measurement period. The Wales Audit Office [11] determined that the cost of unserved meals on 62 wards was approximately $£ 1.5$ million ( $€ 1.7$ million, June 2017) per annum. For an Italian school caterer serving 510 meals per day, Falasconi et al. [12] calculated an economic value of $€ 381.90$ per day for food wasted. Betz et al. [13] calculated that food wasted in two food service institutions amounted to CHF170,216 (€156,742, June 2017) per annum.

Reducing food waste in an organization can be referred to as a continuous improvement process (CIP) as applied in Total Quality Management (TQM) [14]. Such an improvement process generally involves the following steps: Analyze the problem, Identify solutions, Implement measures, and Review results. Whereas most of the above studies analyze the problem or identify solutions (e.g., $[13,15])$, the study presented in this article is innovative, as it involves all steps. The status quo in three food service facilities of the healthcare sector is analyzed, the reasons for food waste are determined, and measures are developed accordingly in a participatory approach. Further, the measures are implemented and their effectiveness is controlled by measuring food waste before and after implementation. The participatory elements applied in the case studies address the need for a comprehensive approach revealed by Sonnino and McWilliam [5], who called for a more integrated approach considering all groups along the food supply chain that encounter food waste at the hospital level. In our study, we take account of the fact that the catering service does not only involve kitchen staff, but also several other independently operating groups of employees in such institutions, such as nurses, dieticians and order assistants, whom we integrate into the development and implementation process. Further, the participatory approach includes steps aimed at raising employees' and customers' awareness of food waste, addressing the gap identified by Kranert et al. [1], who found that there is insufficient knowledge on the emergence of food waste in an organization.

In addition, our study provides key figures (e.g., daily plate waste per person and food wasted in relation to food provided) concerning three German food service facilities from this sector, which can be compared to those provided in other (international) studies. This complements the figures for total waste quantities for the German healthcare sector provided by Kranert et al. [1].

\section{Aims and Objectives}

The aim of the study was to develop measures to counteract food waste in a participatory approach and to test their effectiveness in three different service institutions, taken as case studies. In the participatory approach, interdisciplinary teams were engaged in the development and implementation of measures [16]. The case studies comprise: first, food provision to hospitalized patients in a hospital; second, the catering service of a hospital cafeteria; and third, food provision in a residential home. The effectiveness of the measures was determined by analyzing the quantities of food provided and wasted before and after implementing the measures. Furthermore, this article is aimed at providing practical advice to managers of other healthcare food service institutions wishing to counteract food waste in their organizations. 


\section{Characteristics of the Three Organizations under Investigation}

The case studies involve three German institutions which, for reasons of confidentiality, will be called the (a) hospital, (b) cafeteria, and (c) residential home. Table 1 summarizes the food supply characteristics of these three institutions. The hospital has 367 beds; patients admitted receive three meals per day. The hospital has medical centers for urology, gynecology, general pediatrics, and neonatology. It also has centers for general medicine, internal medicine, cardiac or renal diseases, diabetology, and breast diseases. The hospital also specializes in surgery, especially general, abdominal, hand, trauma, and reconstructive surgery. In the hospital, a tray service is used to supply all three meals. The meals are prepared, portioned, and delivered to the hospital by a central processing kitchen (CPK). Warm dishes are prepared according to the cook \& chill procedure. The hospital kitchen is responsible for regenerating warm food components on the trays and transporting the trolleys with the meals to the wards. After that, the responsibility for food delivery to patients is passed on from the kitchen staff to the nurses. So-called order assistants take patients' orders every morning. Patients choose from a fixed variety of food components for the next day's meals. Breakfast and dinner consist of "bread meals", where patients select the type and number of slices of bread required plus spreads, sliced cheese or meats. They can also opt for yogurt or fresh fruit. In Germany, lunch is traditionally served as a warm meal, consisting of a soup, main dish and dessert. Patients can choose from three main dishes. Special dietary needs are determined by doctors and medical staff, representing the basis for order assistants' requests. Orders are submitted electronically to the CPK.

The second institution, the cafeteria, offers meals, snacks, and drinks to medical staff and hospital guests. Sandwiches, cakes, snacks, and desserts are served throughout the day. In addition, two warm meals are offered at lunchtime, as well as ready-to-serve meals in the afternoon. The warm meal supplied for lunch is also prepared by the CPK. Unlike the lunches served to patients, which are delivered readily portioned on trays, the cafeteria receives bulk containers, which its service staff have to regenerate. Guests decide there and then which dish they want, which is placed directly on a plate by cafeteria staff. All the other food items offered are delivered by local stores and prepared by the cafeteria staff. Sandwiches and rolls are made fresh every day, as well as the salad for the salad lunch buffet and the desserts, which are delivered as convenience products. The ready-to-serve meals available in the afternoon until closure at 5 p.m. are refrigerated convenience products such as schnitzel or meatballs with either salad or rolls. They are either preprepared in the morning and stored cool until ordered, or prepared on request.

The residential home is the third organization under investigation. It accommodates 74 seniors in 69 single rooms and double rooms. The institution's food service facility manages and organizes residents' orders and processes suppliers' deliveries. Residents' rooms are grouped into eight living units, each of which has a multifunctional community room with a kitchen and dining area. Residents can choose whether they want to eat in a group or alone in their rooms. In addition to the living units with long-term residents, the residential home also has a daycare facility where seniors can stay from 8 a.m. to 4 p.m., including breakfast and lunch. 72 of the 74 long-term residents use the meals service regularly; only two residents are fed via a special enteral tube. Food is supplied to residents as follows: a warm lunch is supplied by the CPK (the same one that supplies (a) and (b)). The meal components are supplied in bulk containers and regenerated by the food service department. The residents choose from two different main dishes for lunch, which they order from a menu list the week before. Breakfast and dinner consist of bread meals prepared by the food service facility of the residential home. They can choose different bread or roll varieties and different spreads, sliced meats and cheeses. They are also offered a special dinner component that varies every day, which is either a savory or a sweet dish in addition to the bread ordered. Residents state their preferences for breakfast and dinner once on arrival, after which changes are made regularly. 
Table 1. Summary of food supply characteristics in institutions (a), (b), and (c).

\begin{tabular}{|c|c|c|c|}
\hline & Hospital (a) & Cafeteria (b) & Residential Home (c) \\
\hline \multicolumn{4}{|c|}{ Breakfast } \\
\hline Supplier & $\begin{array}{l}\text { Tray service supplied by central } \\
\text { processing kitchen (CPK) }\end{array}$ & $\begin{array}{l}\text { Snacks, rolls, cakes delivered by local stores and } \\
\text { prepared by cafeteria staff }\end{array}$ & Groceries supplied by wholesaler and local bakery \\
\hline Composition & $\begin{array}{l}\text { Bread meal that patients order daily } \\
\text { from a set list for the next day }\end{array}$ & Individual customer's choice, free-flow system & $\begin{array}{l}\text { Bread meal either prepared by staff according to } \\
\text { residents' stated preferences or individually by } \\
\text { residents in table groups }\end{array}$ \\
\hline \multicolumn{4}{|c|}{ Lunch } \\
\hline Supplier & Tray service supplied by CPK & $\begin{array}{l}\text { Menus supplied in bulk by CPK, regenerated by } \\
\text { cafeteria staff }\end{array}$ & Menus supplied in bulk by CPK, regenerated by staff \\
\hline Composition & $\begin{array}{l}\text { Warm meal that patients order daily } \\
\text { from a menu plan for the next day }\end{array}$ & $\begin{array}{l}\text { Customer places individual order after viewing } \\
\text { the meals, free-flow system (warm meal offered at } \\
\text { lunch time) }\end{array}$ & $\begin{array}{l}\text { Warm meal that seniors order from a menu plan a } \\
\text { week before delivery }\end{array}$ \\
\hline \multicolumn{4}{|c|}{ Dinner $^{1}$} \\
\hline Supplier & Tray service supplied by CPK & $\begin{array}{l}\text { Snacks, cakes delivered by local stores } \\
\text { and wholesaler }\end{array}$ & $\begin{array}{l}\text { Groceries supplied by wholesaler, individual trays } \\
\text { prepared by internal food supply dept. }\end{array}$ \\
\hline Composition & $\begin{array}{l}\text { Bread meal that patients order daily } \\
\text { from a set list for the next day }\end{array}$ & Individual customer's choice, free-flow system & $\begin{array}{l}\text { Bread meal and savory or sweet dish, either prepared } \\
\text { by staff according to residents' stated preferences or } \\
\text { individually by residents in table groups }\end{array}$ \\
\hline
\end{tabular}

${ }^{1}$ Cafeteria closes at 5 p.m. 


\section{Methodology}

\subsection{Phases of the Participatory Concept Applied in the Case Studies}

The aim of the participatory concept [16] applied in the case studies was to increase employee commitment and assumption of responsibility. It analyzed the process of food supply and aimed to develop measures of improvement in collaboration with the different groups of employees involved by making use of their knowledge and experience. The groups included management and kitchen staff, as well as nursing staff and social workers, or even non-employed actors, such as residents' relatives. The concept took up the recommendations of Donini et al. [17], who suggested involving all employee groups to establish a good communication structure for improving the quality of hospital catering services, and of Goonan et al. [15], who stated: "A planning workshop, designed to bring management and kitchen staff together to brainstorm ideas for short- and long-term food waste reduction initiatives, is an obvious place to start."

The participatory concept applied in the case studies was comprised of five phases (cf. Figure 1), beginning with an analysis of the actual state, where in the structures and processes of the food service facilities were identified by process analysis. This analysis was subdivided into a visit and a measurement part, both taking place on-site at the food service facilities, and an off-site analysis phase. In the measurement part, the quantities of food provided and wasted were determined over a two-week measurement period, referred to as the reference measurement (\#1). During the visit phase, relevant information was gathered following observations and interviews. The interviewees were members of the food supply chain, such as service assistants, the kitchen manager, or nursing staff. In the analysis phase of the process analysis, all of the information collected during the interviews, observations, and measurements was evaluated, forming the basis for the next project phase, the development of measures to counteract food waste (cf. Figure 1). The measures were then implemented in Phase 3. In Phase 4 "Review of results", a control measurement (\#2) of food waste was conducted and the results were compared with those of the reference measurement. The effectiveness of the measures implemented was assessed in Phase 5 and, where applicable, corrective actions were proposed to the management of the food service facilities.

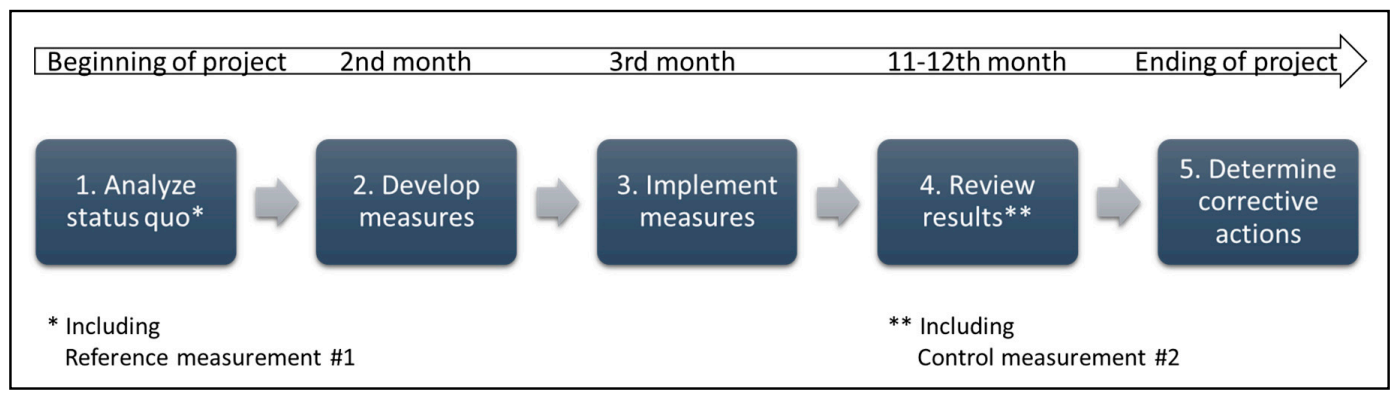

Figure 1. Phases of the participatory concept applied in the case studies (Source: the authors, based on [16]).

\subsection{Measurement: Selection of Waste Categories and Food Classes}

The food waste categories and food classes used in our study were based on the definition given by Betz et al. [13], who subdivided food waste into three categories: preparation losses, serving losses, and plate waste. They subdivided food waste into seven classes: "(1) meat/fish, (2) starch accompaniments, (3) vegetables, (4) fruit, (5) desserts, (6) other (e.g., sauce, soup, ketchup, cheese), and (7) unavoidable losses (e.g., banana skins)". We modified these classes to reduce complexity and simplify the measurement process. Our approach gave us a detailed picture of waste composition, enabling us to develop specifically adjusted measures. 
Table 2 provides an overview of the food waste categories for each meal relevant to our study and the food classes to which losses were allocated. In the cafeteria, meals were split into lunch and other meals, with the latter category including all items sold except for lunch components. For the hospital and the residential home, meals were subdivided into breakfast, lunch, and dinner. In the hospital, only three food classes were applied in order to simplify the separation process in the dishwashing area. The "packaged food" food class analyzed for the hospital includes packaged foodstuffs such as coffee milk, sugar, spreads, cakes, and fresh fruit. The "miscellaneous" food class includes all other foodstuffs served, e.g., lunch dishes, mash, soups, etc. For breakfast and dinner, the third food class "bread" was applied, which includes slices of bread and rolls served to patients.

Table 2. Waste categories (PW: plate waste; SL: serving losses) and food classes applied for each food service facility for reference and control measurements.

\begin{tabular}{|c|c|c|}
\hline Hospital (a) & Cafeteria (b) & Residential Home (c) \\
\hline Breakfast & Other Meals * & Breakfast \\
\hline PW & PW/SL & PW \\
\hline $\begin{array}{ll}\text { - } & \text { Bread } \\
\text { - } & \text { Packaged food } \\
\text { - } & \text { Miscellaneous }\end{array}$ & - $\quad$ Miscellaneous & $\begin{array}{ll}\text { - } & \text { Bread } \\
\text { - } & \text { Sliced meat, cheese, other spreads } \\
\text { - } & \text { Miscellaneous }\end{array}$ \\
\hline Lunch & Lunch & Lunch \\
\hline PW & PW/SL & PW/SL \\
\hline $\begin{array}{ll}\text { - } & \text { Miscellaneous } \\
\text { - } & \text { Packaged food }\end{array}$ & $\begin{array}{ll}\text { - } & \text { Meat/fish/egg-based components } \\
\text { - } & \text { Starch-based components } \\
\text { - } & \text { Vegetables/salad } \\
\text { - } & \text { Dessert } \\
\text { - } & \text { Non-avoidable } \\
\text { - } & \text { Miscellaneous }\end{array}$ & $\begin{array}{ll}\text { - } & \text { Meat/fish/egg-based components } \\
\text { - } & \text { Starch-based components } \\
\text { - } & \text { Vegetables/salad } \\
\text { - } & \text { Dessert } \\
\text { - } & \text { Non-avoidable } \\
\text { - } & \text { Miscellaneous }\end{array}$ \\
\hline Dinner & & Dinner \\
\hline PW & & PW \\
\hline $\begin{array}{ll}\text { - } & \text { Bread } \\
\text { - } & \text { Packaged food } \\
\text { - } & \text { Miscellaneous }\end{array}$ & & $\begin{array}{ll}\text { - } & \text { Bread } \\
\text { - } & \text { Sliced meat, cheese, other spreads } \\
\text { - } & \text { Miscellaneous }\end{array}$ \\
\hline
\end{tabular}

* Other meals include all items sold in cafeteria except for lunch components.

We measured patients', customers', and residents' plate waste for all meals at each institution. In the cafeteria, we also determined serving losses occurring due to bulk delivery from the CPK and other food items sold, such as cakes and sandwiches. For the residential home, we also weighed serving losses occurring due to bulk delivery from the CPK. For breakfast and dinner, this waste category was not applicable (N/A), since residues from meal preparation, such as open packages of cheese or bread are stored and used to prepare the next meals. Serving losses did not apply for patients' food supply in the hospital either because meals consisted of preportioned trays delivered by the CPK.

\subsection{Measurement: Determination of Food Provided and Wasted}

Quantities of food waste were determined by weighing using electronic scales. We decided that exact weighing would be better for our purpose than the visual estimation of food waste described by Kirks and Wolff [18] or Kandiah et al. [19]. Weighing was performed by employees from the three organizations who were trained in advance on how to separate food waste into the specified food classes and, where applicable, distinguish between serving losses and plate waste. Plate waste was documented on weighing lists, including the date, meal, and food class. Serving losses were recorded 
on delivery notes provided by the CPK. Hence it was possible to allocate serving losses directly to the corresponding food component delivered.

The weights of foods provided by the CPK were obtained from delivery notes for the food delivered in bulk containers. The weights of food components preportioned on trays in the CPK were either taken from the enterprise resource planning (ERP) system once the manager had confirmed the validity of the data or from calibration lists obtained from the CPK management. Weights of breakfast and dinner items in the retirement home and quantities of the various articles offered in the cafeteria were provided by the relevant kitchen managers.

\subsection{Measurement: Date and Period}

Two measurements were conducted at each institution; the first is referred to as the reference (\#1) measurement and the second as the control (\#2) measurement. The time span between the two measurements at the three institutions was seven to nine months. During this time, measures aimed at improving resource efficiency, i.e., optimizing the food produced and reducing food waste, were developed and implemented. The waste measurement period was chosen to represent the average eating and food waste producing behavior of patients, customers, and residents. For this reason, we decided not to include bank holidays or holiday periods in the measurement phase and made sure that there was no mass disease outbreak leading to unusual measurements. The intended measurement time was two whole weeks, including weekends.

\subsection{Measurement: Quantitative Analysis of the Results for Food Provided and Wasted}

The waste quantities documented and production figures were processed in MS Excel and statistical analysis was performed using IBM SPSS Statistics 24 . From the given data, the following values were calculated and graphically presented for the first and second measurement (subscript $i$ refers to specific measurement day $i$ and $n$ to the total number of days during the measurement period):

I. Comparison of food provided and wasted as average total waste rate $(\overline{W R})$

$$
\overline{W R}=\frac{\sum_{i=1}^{n} W R_{i}}{n}=\frac{\sum_{i=1}^{n}(\text { food wasted } / \text { food provided })_{i}}{n}
$$

II. Comparison of food provided and wasted (rate of serving losses $(\overline{S L})$, rate of plate waste $(\overline{P W})$ )

$$
\begin{aligned}
& \overline{S L}=\frac{\sum_{i=1}^{n} S W R_{i}}{n}=\frac{\sum_{i=1}^{n}(\text { serving losses } / \text { food provided })_{i}}{n} \\
& \overline{P W}=\frac{\sum_{i=1}^{n} P W R_{i}}{n}=\frac{\sum_{i=1}^{n}(\text { plate waste } / \text { food provided })_{i}}{n}
\end{aligned}
$$

III. Distribution of food wasted among meals as average waste share $(\overline{W S})$

$$
\overline{W S}=\frac{\sum_{i=1}^{n} W S_{i}}{n}=\frac{\sum_{i=1}^{n}(\text { waste per meal } / \text { waste per day })_{i}}{n}
$$

IV. Food provided $(\overline{F P p P})$ and food wasted per meal as serving losses $(\overline{S L p P})$ or plate waste $(\overline{P W p P})$ per person per day

$$
\begin{aligned}
& \overline{F P p P}=\frac{\sum_{i=1}^{n}(\text { food provided per meal } / \text { number of diners })_{i}}{n} \\
& \overline{S L p P}=\frac{\sum_{i=1}^{n}(\text { serving losses per meal } / \text { number of diners })_{i}}{n} \\
& \overline{P W p P}=\frac{\sum_{i=1}^{n}(\text { plate waste per meal } / \text { number of diners })_{i}}{n}
\end{aligned}
$$


The results of the two measurements were compared and change rates were determined. Statistical analysis (two-sided $t$-test for unpaired two samples with $p<0.05$ considered statistically significant) was used to determine whether differences in the values of reference and control measurement were coincidental or could be attributed to the changed settings.

\subsection{Development of Measures Using a Participatory Approach}

Measures, i.e., actions, aimed at improving resource efficiency, were developed in focus group workshops in the period between the reference and control measurements in each of the three organizations. Table 3 summarizes the elements of the focus group workshops and their aims.

Table 3. Elements of focus group workshops conducted as part of the participatory approach and aims of the elements.

\begin{tabular}{|c|c|}
\hline Elements of Focus Group Workshops & Aim of the Element \\
\hline $\begin{array}{l}\text { Presentation of facts and figures related to food waste } \\
\text { in general and organization-specific based on results } \\
\text { of measurement \#1 }\end{array}$ & $\begin{array}{l}\text { - } \quad \text { Creating awareness of the problem } \\
\text { - } \quad \text { Motivating employees }\end{array}$ \\
\hline $\begin{array}{l}\text { Brainwriting [20] (Why do you think food waste } \\
\text { occurs in your organization?) }\end{array}$ & $\begin{array}{l}\text { - } \quad \text { Involving workshop participants } \\
\text { - } \quad \text { Gaining insight into practice } \\
\text { - } \quad \text { Motivating employees }\end{array}$ \\
\hline $\begin{array}{l}\text { Clustering of ideas (What are the main aspects } \\
\text { leading to food waste?) }\end{array}$ & $\begin{array}{l}\text { - } \quad \text { Stimulating debate among participants } \\
\text { - Identifying key points for food waste based on } \\
\text { employees' perspective }\end{array}$ \\
\hline $\begin{array}{l}\text { Joint development of measures (How do you think } \\
\text { food waste could be avoided?) }\end{array}$ & $\begin{array}{l}\text { - } \quad \text { Stimulating debate among participants } \\
\text { - } \quad \text { Developing measures } \\
\text { - } \quad \text { Creating commitment and } \\
\text { psychological ownership }\end{array}$ \\
\hline $\begin{array}{l}\text { Selection of measures to be implemented (Please cast } \\
\text { three votes to the measures you consider best for } \\
\text { avoiding food waste.) }\end{array}$ & $\begin{array}{l}\text { - Democratically prioritizing measures } \\
\text { by participants }\end{array}$ \\
\hline Setting of timeline and to-do list & $\begin{array}{l}\text { - Jointly choosing and prioritizing measures for } \\
\text { implementation to increase acceptability and } \\
\text { create ownership } \\
\text { Defining employees in charge and required } \\
\text { tasks and deadlines to ensure timely } \\
\text { implementation of measures }\end{array}$ \\
\hline
\end{tabular}

The measures were developed in a participatory approach together with representatives from each department dealing with food supply. Focus groups were applied to learn about the psychological and sociological interrelation of the staff involved [21]. Another reason for choosing this approach was that we wanted employees to become very committed to the project, which we attempted to achieve by creating psychological ownership. As Umble and Umble [22] stated, psychological ownership of ideas is critical to generating true enthusiasm and commitment to the project. By becoming involved, employees were supposed to overcome their personal reservations with regard to the anticipated changes. Instead, they should identify with the measures in order to improve their implementation and to obtain sustainable results, i.e., long-lasting effects in improving resource efficiency. The interdisciplinary teams included a number of different participants. In addition to two researchers (one as moderator, one for record keeping) the following employees took part in the workshops. For the hospital, the team included the head of nursing services, two nurses, two order assistants, a dietician, 
the hospital kitchen manager, and a representative from the CPK. For the cafeteria, two members of the service staff, the kitchen manager, a representative from the $\mathrm{CPK}$, and one nursing staff member (in the role of a diner at the cafeteria) took part in the workshop. In the retirement home, the kitchen manager, one service staff member, four nursing staff members, the director, the quality manager, and the social worker participated in the workshops. Table 4 summarizes the measures developed in the project. The measures were structured into five categories information, communication, products, processes, and customer needs. These measures were implemented between measurement \#1 and \#2 (cf. Figure 1).

Table 4. Summary of measures improving resource efficiency in the food service facilities of a hospital (a), cafeteria (b), and retirement home (c).

\begin{tabular}{|c|c|}
\hline Topic & $\begin{array}{l}\text { Summary of Measures, Indication of Relevance in Organization (a) } \\
\text { Hospital, (b) Cafeteria, and (c) Retirement Home }\end{array}$ \\
\hline Information & $\begin{array}{l}\text { - Sensitize employees to the topic of food waste (by providing posters } \\
\text { and involving the management) }(a, b, c) \\
\text { - Train order assistants to optimize order taking (better matching of } \\
\text { ordered quantities to patients' needs) (a) } \\
\text { - } \quad \text { Train cafeteria staff to fill up the salad buffet }(b) \\
\text { - } \quad \text { Sensitize customers to the topic of food waste (design a poster) }(a, b)\end{array}$ \\
\hline Communication & $\begin{array}{l}\text { - Analyze the flow of communication along the supply chain (from CPK } \\
\text { to customer) to identify gaps }(a, b, c) \\
\text { Organize workshops with employees from different departments in } \\
\text { order to improve communication } \\
\text { Establish continuous feedback processes along the supply chain (a, } \\
\text { b, c) } \\
\text { Provide information on the nutrition biography of patients and } \\
\text { residents to the order assistants and personnel concerned }(a, c)\end{array}$ \\
\hline Products & $\begin{array}{l}\text { - Configure food catalogue with detailed description of breakfast and } \\
\text { dinner items (a) } \\
\text { - } \quad \text { Reduce the wide range of items offered for breakfast and dinner, and } \\
\text { review quality (a) } \\
\text { - } \quad \text { Limit deliverable quantities of spreads and toppings to order per } \\
\text { person (a) and link them to ordered quantity of bread slices or rolls (a) } \\
\text { - Introduce fixed assortment for kitchens on wards (a) }\end{array}$ \\
\hline Processes & $\begin{array}{l}\text { - Change order and delivery process to account for new admissions and } \\
\text { discharges better (a) } \\
\text { - } \quad \text { Designate a central person in charge of ward kitchens (a) } \\
\text { Individualize the process of food supply to serve individual needs } \\
\text { better (c) }\end{array}$ \\
\hline Customer needs & $\begin{array}{l}\text { - } \quad \text { Identify and consider target group-specific needs (c) } \\
\text { - } \quad \text { Change portion sizes according to target group-specific standards and } \\
\text { their needs }(a, b, c) \\
\text { - } \quad \text { Train service employees with regard to portion sizes }(b, c) \\
\text { - } \quad \text { Analyze the number of meals consumed and customer preferences to } \\
\text { better meet the number of meals ordered from CPK (b) }\end{array}$ \\
\hline
\end{tabular}




\section{Results of the Reference (\#1) and Control (\#2) Measurements of Food Waste}

\subsection{Summary of Quantitative Results for Waste Measurements}

The results of the quantitative analysis of the reference (\#1) and control (\#2) measurements are summarized in Tables 5 and 6 for the three organizations (hospital, cafeteria, and retirement home).

Table 5. Summarized rates of serving losses, $\overline{S L}$, plate waste, $\overline{P W}$, and total waste, $\overline{W R}$, (in \% \pm standard deviation) per meal for the hospital, cafeteria, and retirement home for measurements \#1 and \#2.

\begin{tabular}{|c|c|c|c|c|c|c|}
\hline & \multicolumn{2}{|c|}{ Serving Losses (\%) } & \multicolumn{2}{|c|}{ Plate Waste (\%) } & \multicolumn{2}{|c|}{ Waste Rate (\%) } \\
\hline & $\# 1$ & $\# 2$ & $\# 1$ & $\# 2$ & $\# 1$ & \#2 \\
\hline \multicolumn{7}{|c|}{ Hospital } \\
\hline Breakfast & \multicolumn{2}{|c|}{$\mathrm{N} / \mathrm{A}$} & $28.7 \pm 9.4$ & $30.3 \pm 9.6$ & $28.7 \pm 9.4$ & $30.3 \pm 9.6$ \\
\hline Lunch & \multicolumn{2}{|c|}{$\mathrm{N} / \mathrm{A}$} & $18.5 \pm 5.2$ & $18.6 \pm 3.6$ & $18.5 \pm 5.2$ & $18.6 \pm 3.6$ \\
\hline Dinner & \multirow{2}{*}{\multicolumn{2}{|c|}{$\mathrm{N} / \mathrm{A}$}} & $45.0 \pm 10.0$ & $42.5 \pm 13.9$ & $45.0 \pm 10.0$ & $42.5 \pm 13.9$ \\
\hline Total & & & & & $25.6 \pm 4.6$ & $26.3 \pm 4.4$ \\
\hline \multicolumn{7}{|c|}{ Cafeteria } \\
\hline Lunch & $23.5 \pm 13.8$ & $16.6 \pm 8.1$ & $3.5 \pm 2.4$ & $1.8 \pm 1.5$ & $27.0 \pm 12.6$ & $18.4 \pm 8.9$ \\
\hline Other & $1.1 \pm 1.4$ & $0.2 \pm 0.3$ & $0.0 \pm 0.0$ & $0.0 \pm 0.0$ & $1.1 \pm 1.4$ & $0.2 \pm 0.3$ \\
\hline Total & & & & & $19.8 \pm 8.3$ & $12.8 \pm 6.6$ \\
\hline \multicolumn{7}{|c|}{ Retirement Home } \\
\hline Breakfast & \multicolumn{2}{|c|}{$\mathrm{N} / \mathrm{A}$} & $12.9 \pm 2.8$ & $7.5 \pm 1.2$ & $12.9 \pm 2.8$ & $7.5 \pm 1.2$ \\
\hline Lunch & $13.4 \pm 9.5$ & $6.2 \pm 3.9$ & $12.5 \pm 4.4$ & $10.9 \pm 2.9$ & $25.9 \pm 10.8$ & $17.1 \pm 3.1$ \\
\hline Dinner & \multirow{2}{*}{\multicolumn{2}{|c|}{$\mathrm{N} / \mathrm{A}$}} & $19.4 \pm 7.9$ & $12.8 \pm 2.6$ & $19.4 \pm 7.9$ & $12.8 \pm 2.6$ \\
\hline Total & & & & & $21.4 \pm 6.7$ & $13.4 \pm 1.4$ \\
\hline
\end{tabular}

Table 6. Summarized quantities of average food wasted per person per day as plate waste, $\overline{\mathrm{PWpP}}$, serving losses, $\overline{\mathrm{SLpP}}$, and food provided, $\overline{\mathrm{FPpP}}$, (in $\mathrm{g} \pm$ standard deviation) for the hospital, cafeteria, and retirement home for measurements \#1 and \#2.

\begin{tabular}{|c|c|c|c|c|c|c|}
\hline & \multicolumn{2}{|c|}{$\overline{\overline{P W p P}}$ (g) } & \multicolumn{2}{|c|}{$\overline{\overline{F P p P}}$ (g) } & \multicolumn{2}{|c|}{$\overline{\mathrm{SLpP}}(\mathrm{g})$} \\
\hline & $\# 1$ & $\# 2$ & $\# 1$ & $\# 2$ & $\# 1$ & $\# 2$ \\
\hline \multicolumn{7}{|c|}{ Hospital ** } \\
\hline Breakfast & $86 \pm 28$ & $75 \pm 24$ & $301 \pm 12$ & $251 \pm 27$ & \multirow{3}{*}{\multicolumn{2}{|c|}{$\mathrm{N} / \mathrm{A}$}} \\
\hline Lunch & $168 \pm 49$ & $127 \pm 29$ & $909 \pm 157$ & $681 \pm 70$ & & \\
\hline Dinner & $131 \pm 29$ & $116 \pm 36$ & $292 \pm 25$ & $277 \pm 40$ & & \\
\hline \multicolumn{7}{|c|}{ Cafeteria * } \\
\hline \multicolumn{7}{|c|}{ Retirement Home } \\
\hline Breakfast & $40 \pm 10$ & $30 \pm 5$ & $309 \pm 47$ & $399 \pm 23$ & \multicolumn{2}{|c|}{$\mathrm{N} / \mathrm{A}$} \\
\hline Lunch & $87 \pm 31$ & $76 \pm 17$ & $702 \pm 96$ & $718 \pm 111$ & $97 \pm 74$ & $46 \pm 32$ \\
\hline Dinner & $75 \pm 31$ & $46 \pm 10$ & $388 \pm 41$ & $363 \pm 47$ & \multicolumn{2}{|c|}{$\mathrm{N} / \mathrm{A}$} \\
\hline
\end{tabular}

Table 5 summarizes the average waste rates $(\overline{W R} \pm$ standard deviation) per meal for the three organizations. Where applicable, the total waste was split into the waste categories serving losses and plate waste. Table 6 summarizes the average daily waste quantities in $g$ occurring per person and per meal ( \pm standard deviation) for the three organizations. For the hospital, only plate waste was relevant, since all meals were provided on trays and any food waste originated entirely from tray waste. In reference to Sonnino and McWilliam [5], plate waste from untouched meals was not recorded separately, but included in the plate waste volume. For the cafeteria, the plate waste per person is also 
calculated. Serving losses were not calculated per person because they occur from excess quantities of meals ordered from the CPK. Serving losses were analyzed separately in Section 5.3. For the retirement home, both daily serving losses and the plate waste per person and per meal were determined.

\subsection{Results for the Hospital (a)}

Data was based on 14 days of measurement in measurement period \#1 and 13 days in measurement period \#2, since data was incomplete for one dinner. The $\overline{W R}$ in the hospital was $25.6 \%$ (\#1) and 26.3\% (\#2) (Table 5). The slight increase between measurements \#1 and \#2 was not statistically significant $(p=0.854)$.

Summing up $\overline{\mathrm{FPpP}}$ for breakfast, lunch, and dinner results in the daily average food provided per person being of $1502 \mathrm{~g}$ for measurement $\# 1$ and $1209 \mathrm{~g}$ for \#2 (cf. Table 6). This represents a 20\% reduction in the average quantity of food served daily per person. Serving losses did not apply, plate waste per person, $\overline{\mathrm{PWpP}}$, decreased by $17 \%$ from $385 \mathrm{~g}$ to $318 \mathrm{~g}$ daily. Both reductions were considered statistically significant, with $p=0.000$ and $p=0.014$, respectively.

For both measurements, lunch created the largest proportion of waste, at $43 \%$ (\#1) and $40 \%(\# 2)$, respectively. Dinner accounted for 34\% (\#1) and 35\% (\#2) of waste; breakfast accounted for the lowest proportion of waste, at $23 \%(\# 1)$ and $25 \%(\# 2)$.

\subsection{Results for the Cafeteria (b)}

Serving losses and plate waste in measurement \#2 were recorded for 14 days, whereas plate waste in measurement \#1 was only recorded for nine days. Results for measurement \#1 were therefore based on the nine-day period. The total waste rate, $\overline{W R}$, for all food provided (Table 5) decreased from $19.8 \%$ to $12.8 \%$, which was a statistically significant $(p=0.036)$ reduction.

Lunchtime $\overline{S L}$ and $\overline{P W}$ fell from $23.5 \%$ to $16.6 \%$ and $3.5 \%$ to $1.8 \%$, respectively. However, the changes were not considered statistically significant $(p=0.143$, and $p=0.052)$ for either waste category. The $\overline{S L}$ for other food products sold fell significantly $(p=0.030)$ from $1.1 \%$ to $0.2 \%$. No plate waste occurred for such products in either measurement. For both measurements, $\# 1$ and $\# 2$, the majority of food waste $(99 \%)$ was produced by lunch.

The food provided per person, $\overline{\mathrm{FPpP}}$, for the warm lunch meal, excluding salad from the buffet, was $602 \mathrm{~g}$ and $662 \mathrm{~g}$ for measurements \#1 and \#2, respectively. The values were calculated without serving losses from excess meals delivered by the CPK. The increase was not statistically significant $(p$ $=0.362)$. The plate waste per person, $\overline{\mathrm{PWpP}}$, was reduced significantly from $36 \mathrm{~g}$ to $18 \mathrm{~g}$ per meal $(p=$ 0.037).

Another analysis performed in addition to waste measurement referred to the number of lunch meals delivered and sold (cf. Table 7). The cafeteria received lunch meals from the CPK and sold them after regenerating bulk containers. An average of $25.1 \%$ of the delivered meals were left unsold in measurement \#1, and $27.2 \%$ in measurement \#2; the slight increase was not statistically significant $(p=0.722)$.

Table 7. Comparison of lunch meals ordered from the central processing kitchen (CPK) and sold in the cafeteria during measurements \#1 and \#2, and average surplus (as a percentage).

\begin{tabular}{|c|c|c|c|c|c|c|c|c|c|c|c|c|c|c|c|}
\hline Day & 1 & 2 & 3 & 4 & 5 & 6 & 7 & 8 & 9 & 10 & 11 & 12 & 13 & 14 & Surplus \\
\hline \multicolumn{16}{|c|}{ Measurement \#1 } \\
\hline Ordered & 105 & 110 & 105 & 105 & 100 & 60 & 70 & 110 & 110 & 130 & 110 & 100 & 60 & 70 & \multirow{2}{*}{$25.1 \%$} \\
\hline Sold & 95 & 110 & 95 & 75 & 87 & 36 & 46 & 81 & 98 & 97 & 62 & 78 & 26 & 48 & \\
\hline \multicolumn{16}{|c|}{ Measurement \#2 } \\
\hline Ordered & 105 & 110 & 100 & 110 & 110 & 45 & 65 & 110 & 110 & 120 & 130 & 95 & 45 & 65 & \multirow[b]{2}{*}{$27.2 \%$} \\
\hline Sold & 84 & 93 & 61 & 84 & 87 & 25 & 38 & 98 & 110 & 89 & 67 & 57 & 28 & 57 & \\
\hline
\end{tabular}




\subsection{Results for the Retirement Home (c)}

During measurement \#1, weighing lists for three days could not be used for analysis owing to inappropriate completion. For this reason, results for \#1 were based on an 11-day period. For organizational reasons, the period for measurement \#2 had to be reduced to one week. The total waste rate determined for \#1 was $21.4 \%$ and $13.4 \%$ in \#2. It was reduced significantly $(p=0.003)$. Both $\overline{P W}$ for breakfast $(12.9 \% / 7.5 \%)$ and dinner $(19.4 \% / 12.8 \%)$ were reduced significantly, with $p=0.000$, and $p=0.049$, respectively, whereas the change for lunch $(12.5 \% / 10.9 \%)$ was not considered statistically significant $(p=0.383)$. However, the serving losses for lunch were reduced significantly $(p=0.043)$ from $13.4 \%$ to $6.2 \%$.

Summing up, the daily food wasted per person results in a total of $300 \mathrm{~g}$ for all meals for measurement \#1 and $199 \mathrm{~g}$ for \#2. The reduction was statistically highly significant $(p=0.009)$. The average quantity of food provided did not change significantly $(p=0.085)$, amounting to $1399 \mathrm{~g}$ for measurement \#1 and $1481 \mathrm{~g}$ for \#2.

Lunch caused the largest share of waste, at 61\% (\#1) and 62\% (\#2) respectively. Dinner accounted for $23 \%$ (\#1) and $22 \%$ (\#2), with breakfast leading to the least waste (15\%) for both measurements.

\section{Discussion}

\subsection{Comparison of the Results Obtained in (a), (b), and (c) with Other Studies}

Several international studies have determined food waste in hospitals. Compared to Williams and Walton [4], who summarized the findings of 32 studies in hospitals, the food waste determined in our hospital, at $25.6 \%$ and $26.3 \%$ discarded in measurements \#1 and \#2, was within the range of $6 \%$ to $65 \%$ and was lower than the median plate waste of $30 \%$ they calculated. Sonnino and McWilliam [5] found that food waste was especially high on elderly rehabilitation wards, determining waste rates of $19 \%$ to $66 \%$ in three Welsh hospitals. Compared to these results, our findings were in the lower range. The findings for our hospital represented an average number for the entire hospital; they were not differentiated by the wards' medical profiles. The findings were also lower than those determined by the Irish Environmental Protection Agency [6], which determined waste rates of 37\% to $49 \%$, and the findings of Ofei et al. [8], who found waste rates of $42 \%$ to $65 \%$, depending on whether or not the service system included a satellite ward kitchen. The results for the reference measurement of $385 \mathrm{~g}$ of average food wasted per person per day coincided with the findings of Goeminne et al. [23], who determined an average of $384 \mathrm{~g}$ of food waste for their control group. With their Meals-on-Wheels distribution approach, they achieved quantities of food waste as low as $81 \mathrm{~g}$ per person per day. Compared to their reduction of $79 \%$ following their intervention to change the service system, our $17 \%$ reduction to $318 \mathrm{~g}$ of food waste was relatively small. This could be attributed to the fact that they offered a more individual catering service style to patients, which took greater account of their specific needs.

In the cafeteria, a surplus of more than one fourth of lunch meals ordered from the CPK coincided with the findings of Garrone et al. [24], who established a model to predict food waste along the supply chain. They stated that the main source of surplus food in the food service industry is due to overproduction following errors in demand forecasting.

Our results for the retirement home were in line with the findings of Hackes et al. [25], who found that a tray service generated more food waste in a retirement community than waiting staff table service and a family-style service. Although lunch food waste (serving losses and plate waste) was reduced to $122 \mathrm{~g}$ per person per day between measurements \#1 and \#2, this value was still higher than the findings of Eriksson et al. [26], who measured $90 \mathrm{~g}$ per person of waste for lunch in an elderly home. This indicated there was further room for improvement. Our findings were in agreement with the findings of Halloran et al. [27], who analyzed food waste reduction options for different actors of the supply chain in Denmark and suggested that production closer to the customer results in less food waste. We also agree with Tincher (in [28]), a consultant to the long-term health-care industry, 
who stated: " ... Food waste is reduced by improving communication systems between the dietary department and the resident or nursing staff ..." . All information available with regard to nutritional requirements needs to be transferred to the kitchen staff who provide the food. For example, nutrition biographies documenting quantities consumed and preferences for special foodstuffs offer valuable information, which should not only be available to nursing staff but also to those who prepare the food.

\subsection{Hospital (a)}

Hospital food waste $(\overline{W R})$ was $25.6 \%$ and $26.3 \%$ in measurements \#1 and \#2. Merely considering these two figures would generate an incomplete picture, which could easily be misinterpreted as stagnation or even a worsening of the food waste situation before and after the implementation of measures. However, considering that both average quantities of food served and wasted per person per day fell significantly by $20 \%$ and $17 \%$, respectively, reveals a different, positive picture.

We could not directly infer a quantitative effect from a specific action, since we did not measure the effectiveness of single interventions. However, we attributed the greatest reduction effects to two actions that were implemented. Firstly, the menu composition and portion sizes were revised by the CPK management. Secondly, the order taking process was improved. The order taking process started with menu assistants asking patients what they want to eat. It also related to the number of items that could be ordered. For example the number of toppings for bread meals was linked to the number of slices of bread or rolls ordered. Initially, some patients ordered a large number of toppings for just two slices of bread to pick so that they could choose what they liked best at the time of consumption. In addition, order assistants were trained not to encourage patients to order additional in-between snacks. The method of offering products has changed. Products were specified in greater detail and the request mode changed. For instance, whereas order assistants used to ask: "Would you like a yogurt and fresh fruit", they then asked: "What would you like to order, cherry yogurt or an apple or a pear or an orange?" While in the first case, patients ordered both with a single "Yes", not knowing exactly what they were getting, they then needed to decide precisely and state what they want. We also found that it is crucial for information about patient discharges and admissions to be transferred to the kitchen immediately in order to reduce overproduction and unnecessary meals. This measure also enhanced patient satisfaction, because it was annoying for patients to receive a different meal to the one ordered simply because they had been transferred from one ward to another. Analyzing flows of information on patient nutrition, especially at departmental interfaces, provided a useful picture and created impetus for further improvement and missing feedback loops.

All measures together have led to a reduction in the average food quantity provided per patient from $1502 \mathrm{~g}$ in the first measurement to $1209 \mathrm{~g}$ in the second one. The revised plans comply with DGE (German Association for Nutrition) standards nevertheless, and guarantee sufficient nutrient intake for patients.

\subsection{Cafeteria (b)}

The food left on plates in the cafeteria at lunch time, $\overline{\mathrm{PWpP}}$, was relatively low in measurement $\# 2$, at $18 \mathrm{~g}$. This was the lowest value compared to lunch plate waste in the hospital (126 g) and retirement home $(76 \mathrm{~g})$. This result could be attributed to several facts: firstly, customers chose what they wanted to eat immediately before consuming the food, to suit their appetite. They did not need to choose their food a day or a week in advance. Secondly, they saw and smelt what they were ordering and were given no surprises. Thirdly, they had to pay for their food at the till in the cafeteria, unlike the hospital patients and residents, who paid indirectly by way of their contributions to health insurance or residential living expenses. There was no plate waste for other foodstuffs apart from lunch. In addition to the three main reasons mentioned above, this could also be attributed to the fact that some of these items are consumed outside the cafeteria, where it was not possible to detect any waste incurred.

Serving losses, $\overline{S L}$, at lunch, including leftovers from warm meals delivered by the CPK and from the salad buffet, were $23.5 \%$ (\#1) and $16.6 \%$ (\#2) of the volume produced. However, the reduction 
was not statistically significant $(p=0.143)$. There was still a high proportion of unsold warm meals, which remained at a constant level of around one in four meals being discarded (see Table 7). The kitchen manager stated that the main reason for the high level of serving losses from warm lunch components was the unpredictable number of consumer orders. The number of meals ordered varied for several reasons. In general, demand at the weekends was lower than on weekdays. An analysis of past menus showed that no rules could be applied to lunch menu preferences. Whereas a certain menu was preferred in one menu cycle, it differed in the next menu cycle. Past shortages have led to unsatisfactory situations, resulting in customer complaints, mainly from hospital staff having lunch at the cafeteria. The management wanted to avoid dissatisfaction due to insufficient food quantities, so a safety margin is applied, often resulting in excess quantities.

Serving losses for other foodstuffs sold during the day were low in measurement \#1 and \#2, at $1.1 \%$ and $0.2 \%$. The alignment of the quantities produced and ordered was optimized by using cooled convenience products, which could be stored and sold over longer periods. The quantity of freshly delivered products such as rolls and sandwiches were prepared exactly in accordance with quantities demanded. Rather than supplying excess quantities, it was considered acceptable for some items to be sold out.

Overall, concepts needed to be developed to deal with the excess of lunch meals delivered by the CPK and not sold to customers.

\subsection{Retirement Home (c)}

The average total waste fell by $37 \%$, from $21.4 \%$ to $13.4 \%$. This was a highly significant reduction following the implementation of several measures developed specifically for the retirement home. These measures were related to the catering situation, residents' needs, and the staff involved. In measurement \#1, the food service facility prepared most meals in the central kitchen of the retirement home and then delivered trays to the dining area of each living unit. After delivery, nursing staff were responsible for distributing the food to the residents. As a consequence, personnel preparing the food (kitchen staff) had no direct contact to residents. This process was optimized by closing the gap between kitchen staff and residents. The entire catering situation was revised, leading to the following situation: at mealtimes, kitchen staff worked within the kitchen areas of each living unit, supporting the nursing staff. Contact between kitchen staff and residents became much closer, leading to a more individual catering situation. Residents' specific daily needs, such as a large appetite or the wish to change sandwich spreads, were more likely to be noticed and could be applied immediately to the composition of each meal. Moreover, if a senior had an infection or a loss of appetite, portion sizes could be reduced accordingly. This reorganization of the food supply situation helped decrease food waste per person from $300 \mathrm{~g}$ to $199 \mathrm{~g}$.

Moreover, it was very useful to have detailed facts about the waste categories. Measurement \#1 revealed that serving losses contributed most to food waste. Hence, an emphasis was placed on developing measures aimed at reducing serving losses. In order to overcome this problem, the kitchen manager changed the lunch preparation process by regenerating smaller batches. More food was then only regenerated when specifically ordered. This was also the case for meat products, for example. Hence the cooling chain was not interrupted and chilled lunch components delivered by the CPK were kept for later use (e.g., for preparing a savory dish, such as macaroni or beef salad for dinner).

Compared to the hospital, less food waste was generated per person per day (\#2: hospital $318 \mathrm{~g}$, retirement home $199 \mathrm{~g}$ ). This could be attributed to the fact that more individual needs were considered in the retirement home.

It was vital to ensure that our objective of reducing food waste would not contribute to malnutrition in the elderly. The case studied showed that the two principles of (a) enhancing the nutritional situation by bringing kitchen staff closer to residents and applying a more individual catering approach in the institution and (b) decreasing food waste can go hand in hand. 


\section{Conclusions}

It was possible to improve the process of food supply in all three organizations (hospital, hospital cafeteria, retirement home), leading to significant reductions in food waste. A comparison of the three organizations revealed that less food waste was generated in the retirement home, where demand could be planned relatively precisely. It was not possible to precisely predict the demand for meals required for hospitalized patients or those sold in the cafeteria; this led to untouched reserve meals in the hospital and serving losses in the cafeteria.

Five major categories of measures were identified: information, communication, products, processes, and customer needs. Food service facilities supplying the healthcare sector need to consider the specific characteristics of their target market, i.e., for the five categories:

- Information: Sensitization to the topic of food waste is important since employees and customers need to understand the relevance of reducing food waste. Visualizing the quantities of food waste (e.g., by calculating the number of disposed yogurts or wasted meat portions per year or by calculating the economic loss associated with food waste) helps with transferring the message to the relevant stakeholders. Moreover sensitization must not only be targeted to employees or customers. It must also address relatives who take care of their family members. Relatives should be aware that measures such as reducing portion sizes are aimed at reducing food waste rather than saving costs at the expense of patients or residents.

- Communication: The food supply chain in the healthcare sector usually involves nursing staff or other assisting personnel. Managers should analyze the flow of communication along their supply chain from the kitchen to the customer, and improve communication especially at departmental interfaces (e.g., organizing workshops with employees from the different stages, such as nurses, dieticians, kitchen and service staff, and order assistants, to improve communication). They should further establish continuous feedback processes along the supply chain. For instance, this could involve determining the process of handing over the residents' nutrition protocols when shifts change in a residential home.

- Products: Depending on the type of service and order taking process applied, patients and residents are unable to see and smell the food they order. For hospitals, we recommend introducing food catalogues or menus that precisely define foodstuffs. If patients know exactly what they are ordering, e.g., strawberry jam rather than just jam, or raspberry yogurt rather than just fruit yoghurt, they are less likely to waste it. We recommend using a target group-specific language when creating menus. Modern terms used in trendy restaurants will not be appropriate in residential homes and may lead to misunderstandings and confusion about the food being served.

- Processes: Managers should change order and delivery processes to take better account of new admissions and discharges in hospitals, and designate a central person to be in charge of ward kitchens. If possible, the process of food supply should be individualized to better serve individual needs. A regular feedback process on food waste, including all stages of food supply from the kitchen to residents / patients, should be installed to raise awareness of food waste and to transfer information on wasted items to the relevant staff in the kitchen. An example is the introduction of food waste protocols which must be completed by the staff of the dishwashing area on a daily basis and which deliver information on serving losses and plate waste for the kitchen staff planning and cooking the meals.

- Customer needs: Hospitalized patients and residents have specific needs that need to be identified, such as their health status and dietary needs, as well as their customs and habits. Menu composition and the description of components should be adapted to the target group. Elderly people like different food to younger people, and need it to be prepared to suit their needs, e.g., softer vegetables or gravy to facilitate chewing and swallowing. Kitchen staff need to understand their customers' specific dietary needs and eating habits. Making residents' nutrition biographies 
available to food service assistants helps them to understand the specific needs of residents and patients.

Creative solutions are necessary to optimize the organization-specific processes of food supply in the healthcare sector. Generally, a shifting of food waste along the supply chain should be avoided [29]. Reducing plate waste by an increased individualization of food supply should not result in larger serving losses.

\section{Need for Further Research and Limitations of the Study}

The following limitations apply to the study. We analyzed the food waste situation before and after implementing all measures at once. For this reason, we cannot directly infer a quantitative effect from a specific measure. Moreover, the reference and control measurements took place in different seasons. The food waste level may have been affected by different weather conditions. Moreover, the menu composition in measurements \#1 and \#2 was different. Hence, if customers preferred some menus in one of the measurements, this may also have influenced the results. The duration of measurement \#2 in the retirement home was reduced to seven days for organizational reasons. This shorter measurement period may also have affected the food waste level identified. If the menu contained preferred menus during this period, this may have led to a lower food waste level. Another limitation refers to the separation of food waste into food classes. In the hospital, it was not possible to separate food waste into the same food classes as in the retirement home and the cafeteria for organizational reasons. This meant that a comparison of food classes among all three organizations was not possible.

Future research should test the effectiveness of individual measures to counteract food waste. To this end, food waste should be measured before and after single interventions.

Further research should also focus on how to identify and overcome weaknesses in communication structures, and on how to integrate all employees involved in order to gain their commitment in organizational change processes.

In addition, target group-specific needs and expectations should be studied more closely to better match the characteristics of the food delivered and expected by customers. This includes meal composition and preferences, as well as the atmosphere of the dining area and the presentation of meals on menus.

The results revealed the importance of having meaningful key figures. Future research should therefore identify sector-specific key figures in order to establish benchmarks, which enable companies of the food sector to assess their own position in comparison to others.

Support of the management is a basic requirement for the success of food waste reduction projects. Managers should therefore be convinced that food waste reduction will be worthwhile from an economic perspective. Hence, researchers should also further investigate how to economically evaluate their findings on food waste reduction.

Acknowledgments: This study was part of the German-Dutch INTERREG IV A project “Nachhaltig Gesund/Duurzaam Gezond" co-financed by the European Regional Development Fund (ERDF) and the Dutch province of Gelderland, and the Ministry for Climate Protection, Environment, Agriculture, Conservation and Consumer Protection of the German State of North Rhine-Westphalia. The project was supervised by the EUREGIO Rhine-Waal program management (funding code: "Duurzaam Gezond" III-1-03=018.10).

Author Contributions: Silke Friedrich and Petra Teitscheid conceived the design of this study. Christina Strotmann conducted the case studies and wrote the paper. Guido Ritter and Judith Kreyenschmidt supervised the work.

Conflicts of Interest: The authors declare no conflict of interest. The founding sponsors had no role in the design of the study; in the collection, analyses, or interpretation of data; in the writing of the manuscript, or in the decision to publish the results. 


\section{References}

1. Kranert, M.; Hafner, G.; Barabosz, J.; Schneider, F.; Lebersorger, S.; Scherhaufer, S.; Schuller, H.; Leverenz, D. Determination of Discarded Food and Proposals for a Minimization of Food Wastage in Germany: Abridged Version; University Stuttgart Institute for Sanitary Engineering: Stuttgart, Germany, 2012.

2. Von Koerber, K. Fünf Dimensionen der nachhaltigen ernährung und weiterentwickelte grundsätze: Ein update. Ernährung Fokus 2014, 14, 260-268.

3. Rückert-John, J. Natürlich Essen: Kantinen und Restaurants auf dem Weg zu nachhaltiger Ernährung; Campus Verlag: Frankfurt am Main, Germany, 2007.

4. Williams, P.; Walton, K. Plate waste in hospitals and strategies for change. Eur. e-J. Clin. Nutr. Metab. 2011, 6, 235-241. [CrossRef]

5. Sonnino, R.; McWilliam, S. Food waste, catering practices and public procurement: A case study of hospital food systems in Wales. Food Policy 2011, 36, 823-829. [CrossRef]

6. Environmental Protection Agency; Green Healthcare Programme. Reducing Food Waste in Irish Hospitals Results, Guidance and Tips from a 3-year Programme; Green Healthcare Programme: Dublin, Ireland, 2013.

7. Dias-Ferreira, C.; Santos, T.; Oliveira, V. Hospital food waste and environmental and economic indicators-A Portuguese-case study. Waste Manag. 2015, 46, 146-154. [CrossRef] [PubMed]

8. Ofei, K.; Holst, M.; Rasmussen, H.; Mikkelsen, B. How practice contributes to trolley food waste. A qualitative study among staff involved in serving meals to hospital patients. Appetite 2014, 83, 49-56. [CrossRef] [PubMed]

9. Engström, R.; Carlsson-Kanyama, A. Food losses in food service institutions: Examples from Sweden. Food Policy 2004, 29, 203-213. [CrossRef]

10. Barton, A.; Beigg, C.; MacDonald, I.; Allison, S. High food wastage and low nutritional intakes in hospital patients. Clin. Nutr. 2000, 19, 445-449. [CrossRef] [PubMed]

11. Wales Audit Office: Hospital Catering and Patient Nutrition. Available online: http://www.audit. wales/system/files/publications/Hospital_Catering_and_Patient_Nutrition_English_2011.pdf (accessed on 3 July 2017).

12. Falasconi, L.; Vittuari, M.; Politano, A.; Segrè, A. Food waste in school catering: An Italian case study. Sustainability 2015, 7, 14745-14760. [CrossRef]

13. Betz, A.; Buchli, J.; Göbel, C.; Müller, C. Food waste in the Swiss food service industry—Magnitude and potential for reduction. Waste Manag. 2015, 35, 218-226. [CrossRef] [PubMed]

14. Brüggemann, H.; Bremer, P. Grundlagen Qualitätsmanagement: Von den Werkzeugen Über Methoden zum TQM, 2nd ed.; Springer: Wiesbaden, Germany, 2015. (In German)

15. Goonan, S.; Mirosa, M.; Spence, H. Getting a taste for Food Waste: A mixed method ethnographic study into hospital food waste before patient consumption conducted at three New Zealand foodservice facilities. J. Acad. Nutr. Diet. 2014, 114, 63-71. [CrossRef] [PubMed]

16. Strotmann, C.; Göbel, C.; Friedrich, S.; Kreyenschmidt, J.; Ritter, G.; Teitscheid, P. A participatory approach to minimizing food waste in the food industry-A manual for managers. Sustainability 2017, 9, 66. [CrossRef]

17. Donini, L.M.; Castellaneta, E.; de Guglielmi, S.; de Felice, M.; Savina, C.; Coletti, C.; Paolini, M.; Cannella, C. Improvement in the quality of the catering service of a rehabilitation hospital. Clin. Nutr. 2008, 27, 105-114. [CrossRef] [PubMed]

18. Kirks, B.A.; Wolff, H.K. Comparison of methods for plate waste determinations. J. Am. Diet. Assoc. 1985, 85, 328. [PubMed]

19. Kandiah, J.; Stinnett, L.; Lutton, D. Research: visual plate waste in hospitalized patients: Length of stay and diet order. J. Am. Diet. Assoc. 2006, 106, 1663-1666. [CrossRef] [PubMed]

20. Klebert, K.; Schrader, E.; Straub, W.G. Moderations-Methode: Das Standardwerk, 3rd ed.; Windmühle: Hamburg, Germany, 2006.

21. Kepper, G. Methoden der Qualitativen Marktforschung. In Handbuch Marktforschung: Methoden, Anwendungen, Praxisbeispiele, 3rd ed.; Gabler: Wiesbaden, Germaby, 2008.

22. Umble, M.; Umble, E. Overcoming resistance to change. Ind. Manag. 2014, 56, 16-21.

23. Goeminne, P.; de Wit, E.; Burtin, C.; Valcke, Y. Higher food intake and appreciation with a new food delivery system in a Belgian hospital. Meals on wheels, a bedside meal approach. Appetite 2012, 59, 108-116. [CrossRef] [PubMed] 
24. Garrone, P.; Melacini, M.; Perego, A. Opening the black box of food waste reduction. Food Policy 2014, 46, 129-139. [CrossRef]

25. Hackes, B.L.; Shanklin, C.W.; Kim, T.; Su, A.Y. Tray service generates more food waste in dining areas of a continuing-care retirement community. J. Am. Diet. Assoc. 1997, 97, 879-882. [CrossRef]

26. Eriksson, M.; Persson Osowski, C.; Malefors, C.; Björkman, J.; Eriksson, E. Quantification of food waste in public catering services-A case study from a Swedish municipality. Waste Manag. 2017, 61, 415-422. [CrossRef] [PubMed]

27. Halloran, A.; Clement, J.; Kornum, N.; Bucatariu, C.; Magid, J. Addressing food waste reduction in Denmark. Food Policy 2014, 49, 294-301. [CrossRef]

28. McCaffree, J. Reducing foodservice waste: Going green can save green. J. Am. Diet. Assoc. 2009, 109, $205-206$. [CrossRef] [PubMed]

29. Göbel, C.; Langen, N.; Blumenthal, A.; Teitscheid, P.; Ritter, G. Cutting food waste through cooperation along the food supply chain. Sustainability 2015, 7, 1429-1445. [CrossRef]

(C) 2017 by the authors. Licensee MDPI, Basel, Switzerland. This article is an open access article distributed under the terms and conditions of the Creative Commons Attribution (CC BY) license (http:/ / creativecommons.org/licenses/by/4.0/). 